Brenda Keogh and Stuart Naylor are both writers, researchers and professional development providers at Millgate House Education. Jane Maloney is Acting Deputy Director at the Science Learning Centre, University of London Institute of Education. Shirley Simon is Head of Department of Geography, Enterprise, Mathematics and Science at the University of London Institute of Education.

\title{
BRENDA KEOGH
}

Millgate House Education

brendakeogh@millgatehouse.co.uk

\section{STUART NAYLOR}

Millgate House Education

stuartnaylor@millgatehouse.co.uk

\section{JANE MALONEY}

Institute of Education, University of London

j.maloney@ioe.ac.uk

\section{SHIRLEY SIMON}

Shirley Simon, Institute of Education, University of London

s.simon@ioe.ac.uk

\section{Puppets and engagement in science: a case study}

\begin{abstract}
The PUPPETS Project set out to determine whether the use of hand-held puppets would help teachers change the nature of their whole class discourse to enhance children's talk and engagement in primary science lessons. The research provided evidence of an increase in discourse focused on argument and reasoning, and a positive impact on children's engagement and motivation. This case study focuses on one of the strategies (demonstration lessons) used to help teachers implement key findings from the PUPPETS Project research. Data were gathered from groups of teachers who observed demonstration lessons. The purpose of the case study was to explore the value of demonstration lessons as a potential model for teacher professional development within the PUPPETS Project. Teachers responded positively to the demonstration lessons and engaged in significant professional dialogue about the use of puppets that mirrored findings from the original research. Their response suggests that demonstration lessons provide a useful complement to the strategies currently used for teacher professional development.
\end{abstract}

\section{INTRODUCTION}

The PUPPETS Project is a research and development project, funded by the Nuffield Foundation, that aims to help teachers provide more opportunities for productive talk in science lessons, using hand-held puppets as a stimulus. The research examines the effectiveness of hand-held puppets for engaging primary school children's attention, challenging their ideas and promoting learning conversations in science.

The value of talk in children's learning is well-documented. Vygotsky's (1978) work on language and social interaction has been built on by Mercer and his colleagues in their research into classroom interactions (e.g. Mercer, Wegerif \& Dawes, 1999). These and others have found that talking about their ideas helps children to clarify their thinking and develop their capacity to reason (Kuhn, Shaw \& Felton, 1997; Venville, 2002). The amount and nature of children's talk in science lessons depends on decisions made by the teacher. The opportunities provided for talk, the stimulus to generate talk and the learning environment to support talk are all determined by 
teachers. However, research such as Newton, Driver and Osborne (1999) and Alexander (2006) indicates that in many science classrooms teachers do not create circumstances that maximise children's talk, and that the amount of learning conversations is restricted. Reasons for this may include the uncertainty teachers have about the value of children's conversations, limited knowledge of appropriate teaching strategies, and insecure subject knowledge (Osborne \& Simon, 1996; Solomon, 1998).

The initial research set out to investigate whether the use of puppets can provide a stimulus that will generate and support the kind of talk that helps thinking and reasoning in science. There is evidence that the use of puppets can have a valuable impact in engaging children (Low \& Matthew, 2000), and the use of puppets is already well established in primary schools in areas such as drama and social education (Thorp, 2005). The aim was to use puppets to help teachers enhance their practice in science teaching, by increasing the opportunities for children's talk that promotes thinking and reasoning, and becoming more dialogic in their teaching (Alexander 2006). The research questions addressed were:

1. In what ways can puppets be used to enhance children's engagement and promote learning conversations in science?

2. Is it possible to change teachers' beliefs about the value of children's talk and their management of talk in science lessons by using puppets for teaching science?

The initial research included a pilot study involving eight teachers working across the primary age range. An analytical framework was developed using an open-coding approach (Strauss \& Corbin, 1998), in which transcripts of conversations involving teachers, puppets and children were provisionally coded. The coding system was discussed between researchers and refined during the study.

A further 16 primary teachers, teaching across the 7 - 11 age range, were involved in the main study. They were observed and video-recorded teaching a typical science lesson to provide a baseline against which future lessons could be compared. After a period of several weeks, a lesson in which puppets were used in science teaching was video-taped and the teacher was interviewed about the impact of the puppets in their lessons. For each teacher, both of the lessons observed were based on their normal science curriculum; the puppets lessons were not 'special' in any other respect.

Interviews with groups of children were video-recorded to provide data from the children's perspective, and some audio-recording of small group conversations was undertaken. A follow-up meeting with the teachers provided feedback on the longer-term impact of using puppets, including whether and how they continued to use puppets in their science lessons.

These research questions have been reported on elsewhere (e.g. Naylor, Keogh, Downing, Maloney \& Simon, 2005; Simon, Naylor, Keogh, Maloney \& Downing, 2008). The outcomes for both research questions were extremely positive. When puppets were used to present problems to children in science lessons, their engagement and motivation increased, more children were willing to articulate their ideas, and children explained and justified their ideas more. Teachers also changed their professional practice. They emphasised children's talk more in their planning, asked more reasoning and fewer recall questions, and spent more time creating a positive learning environment in science lessons. Teachers generally were very aware of the impact of the puppets on children's responses and the implications for their own professional practice. However some pedagogical issues were raised in the research that teachers did not identify. For example, analysis of the lessons highlighted the negative impact of adult intervention on children's talk and involvement, regardless of whether or not puppets were used. None of the teachers noted this in their reflections on their teaching. 
On the strength of the research data, funding and support were obtained from GlaxoSmithKline and Millgate House Education to implement a substantial programme of professional development (training for 9000 teachers) and provide complementary resources for teachers. The professional development programme provides further opportunities to add to the research data on the effectiveness of puppets in teaching science.

The professional development programme uses a combination of hands-on experience, video clips, discussion and reflection to develop understanding and skills. The programme has been the focus of an independent evaluation (Shakespeare, 2008), which showed that it has had a very positive impact on teachers' professional practice and children's responses to the puppets.

The research reported on here considers an unusual aspect of the professional development programme, using a case study approach. The case study focuses on a series of demonstration lessons, using puppets with classes of children, which were observed by groups of primary teachers. The demonstration lessons were organised by a local authority adviser who was interested in the value of this form of professional development. The lessons were delivered by a member of the PUPPETS Project team (hereafter referred to as the expert teacher), who also led the follow up discussion. The follow up to the lessons provided an opportunity to collect additional data on the use of puppets in teaching science and on the value of this approach to professional development.

The demands of getting a class of children and large numbers of teachers into the same venue at the same time make demonstration lessons potentially difficult to organise. They are also demanding on expert teacher leading the lessons. These demands need to be balanced against the potential gains for the teachers. There is evidence that demonstration lessons can be a valuable form of professional development for teachers (Loucks-Horsley, Love, Stiles, Mundry \& Hewson, 2003). Would demonstration lessons enable teachers to accommodate ideas from the main PUPPETS Project research? These demonstration lessons enabled the following research question to be addressed: to what extent might demonstration lessons be valuable as a means of teacher professional development, related to the PUPPETS research?

\section{METHODOLOGY}

The case study reported on here involved a series of five demonstration lessons using a puppet, taught to children age $6-9$ years. The lessons took place at a large venue, where the children were taught at the front of the room with the teachers gathered around the back of the room, acting as observers. After the lesson the children left and the expert teacher remained with the teachers to reflect on the experience. The teachers were aware that the purpose of the demonstration lessons was to enable them to act in the role of researchers in collecting data that would then be used in an analysis of the lessons.

There was no prior relationship between the children and the expert teacher taking the demonstration lessons. They met for the first time at the start of the lesson. Each lesson began with the expert teacher introducing a puppet to the children. The puppet talked to the children about how it had a problem, then asked the children for help. In small groups the children discussed how they might be able to solve the problem, then they explained to the puppet how they thought the problem might be solved. A limited amount of equipment was provided so that the groups of children could carry out simple practical investigations to solve the problem. In each lesson the children carried out a practical investigation of their choosing, then engaged in a plenary discussion to share their ideas and decide whether they had solved the problem. Finally they explained to the puppet how they felt the problem could be solved. The focus for each lesson was materials, including fitness for purpose, thermal insulation, and water absorbency. 
For example, in one demonstration lesson Ricky, the puppet, had a problem which was explained through a short story about visiting a fish and chip shop. The owner wrapped his customers' chips (French fries) in decorative wrapping paper, so that they looked like presents. His customers were very pleased with this idea. When Ricky had visited the shop, it was raining. His parcel of chips had got wet in the rain and some of his chips had fallen out onto the floor. His grandma also found that the colour from the wrapping paper ran onto her chips when her parcel got wet in the rain. Ricky asked the children for help in solving the problem of which wrapping paper would be most suitable for the owner of the fish and chip shop to use. This led into a short practical activity to test different types of wrapping paper against a number of criteria, such as wet strength and colour-fastness. A short plenary discussion concluded with the children identifying which papers met the different criteria, then explaining to Ricky which kind of paper would be best and what Ricky should say to the owner of the shop. The stories used with the children were taken from a Spellbound Science storybook (Keogh \& Naylor, 2007), in which the lead characters are all modelled on puppets.

The purpose of the demonstration lessons was to provide a common experience which would act as a basis for discussion and reflection by the teachers (Loucks-Horsley et al, 2003). Each lesson attempted to incorporate a set of pedagogic principles, which had emerged from previous research. These principles including the following:

- the value of children's talk in science lessons

- creating a sense of purpose for children's activity

- starting a lesson with questions and problems, not information and instructions

- providing a meaningful context for science-based activity

- children's ideas being viewed as important and influencing the course of the lesson

- teachers suspending judgement about children's ideas

- children being given time and space to think and talk

Each of the five lessons was observed by approximately 30 - 40 primary school teachers (total number $=178$ ). The teachers had the opportunity to move around during the lesson and observe different groups of children if they wished. They were asked to offer simple practical support if it was clear that any of the children needed assistance (e.g. they needed help in using scissors, or finding the end of a roll of sellotape). They were requested not to offer guidance to the children, provide information, explain what to do, or intervene in more significant ways.

At the end of each lesson, the teachers discussed in groups what they had observed and attempted to identify significant factors that appeared to influence the nature of the lesson. They were asked to concentrate on factors that they judged were important in enabling the puppet to capture the children's attention and engage them effectively during the lesson, and to identify any pedagogic issues that they felt had emerged. A plenary discussion enabled the teachers to explain their views and justify why they thought certain factors were important, based on their observations during the lesson. In this way a consensus view could emerge about which factors were generally viewed as significant, and what professional learning had occurred. Data were collected about the issues raised by each group. The teachers also provided some brief written feedback at the time. Two teachers also provided more extensive feedback immediately after the event by email.

The teachers did not know the children that they were observing, so they were not able to make any comparative judgements about the class that they observed. What they were able to do was draw on their professional expertise and anticipate how other classes might have responded in similar circumstances, but inevitably this makes any conclusions that they reached somewhat tentative. 


\section{DATA AND DATA ANALYSIS}

All of the teachers commented favourably on the impact of the puppet in the lesson. No teachers indicated that the puppet's impact had been anything other than very positive. There was widespread agreement that the children were highly engaged by their conversations with the puppet, motivated to solve the problem presented by the puppet, and eager to let the puppet know what they had found out. Teachers expressed the view that they were keen to go back to school and work with their own children, using a similar approach to teaching and learning science. Comments from teachers included:

\section{This was a very motivating session.}

Throughout the whole presentation the children were transfixed; their eyes never left the puppet's face whilst it was speaking.

The children spoke directly to Ricky (the puppet) and . . . the puppet echoed their thinking. . . and spoke encouragingly to the children.

The children were focussed on the task in hand and worked quickly...

The children were highly focused on the follow up practical activity. They stayed on task and worked with a clear sense of purpose to solve the problem.

These comments are consistent with data from the main study, which showed that puppets can have a positive impact on children's engagement and motivation, and that children had high levels of concentration, they stayed on task and they were eager to contribute to discussion.

The teachers involved in the demonstration lessons also considered aspects of pedagogy. Through discussion and feedback they identified a number of factors that they believed contributed to the high levels of engagement shown by the children. Again many of these mirrored the factors identified by researchers and teachers in the main research. These included the following.

- The puppet character, and the story it told, created an authentic problem that children were keen to solve in order to help the puppet. The children spoke directly to the puppet about its problem. This led to high levels of motivation amongst the children. When children meet a teacher for the first time, they typically require an adjustment period while they develop a relationship with that teacher. The use of a puppet appeared to greatly reduce this adjustment period and to engage children very quickly.

- The children empathised with the puppet. They understood the problem that the puppet had, and they felt sorry for the puppet because it had the problem. The everyday situation described by the puppet made links with the children's personal experience. The children could identify with the situation, and this enhanced their motivation. They worked hard to articulate and explain their ideas to the puppet (who doesn't understand), rather than for the teacher (who 'knows all the answers and will know what they mean even if they don't explain well').

- The combination of the use of a puppet, the narrative through which the problem was described, and the dialogue with the children, all served to present plausible alternative ideas. There was no single obvious solution to the problem, but rather a choice of alternative possibilities. This generated cognitive conflict in the children, and led to very focused discussions in an attempt to resolve that conflict.

- The puppet's role was to be uncertain and unsure about what to do. Because the puppet did not understand, the children felt that they had to help him. Although the children recognised 
that the teacher would know the answer, the puppet did not know the answer, so there was an obvious need to help the puppet. The puppet was viewed as a peer by the children, without the status and authority of the teacher. The puppet was able to present ideas that the children viewed as authentic, even though they would not readily have accepted the same ideas from the teacher. One of the teachers noted that the problem could easily have been introduced by the expert teacher, but that 'he was unlikely to have the same level of motivation from the children. Through the puppet the teacher was able to put forward an idea that was wrong. If the teacher had done this, the children would soon realise that they had been led on. However the main advantage was the children really thought they were helping the puppet and their efforts were directed into finding a solution to his problem.'

- Both the expert teacher and the puppet suspended judgement about the children's ideas. When children put forward their ideas about how to solve the problem, all of the comments about their ideas were encouraging and non-judgemental. This encouraged the children to explain further, to justify their ideas, and to find out more in order to convince the puppet that they could solve its problem.

- The puppet took on the role of the least knowledgeable member of the class, which appeared to be helpful for the children who might lack the confidence to share their ideas. They were more likely to feel comfortable speaking with a puppet who knows less than they do. In this respect the impact on less confident or low attaining children is likely to be particularly noticeable.

Teacher intervention was minimal while children were investigating the problem. This gave the children time and space to think about how they might solve the problem, and to feel a large degree of ownership of how to deal with the problem. Having the opportunity to devise their own solutions to the problem appeared to help keep them focused and motivated. However it was noted that some teachers found it impossible not to intervene and direct the children towards a solution, even though they had been asked not to do this. One teacher described her feelings as ' $I$ found myself itching to get involved! I . . had to physically move myself away from the boys as I knew I would want to intervene, or be bossy! When the boys did start their investigation they worked systematically and quickly. They had taken a long time to get going, but now they seemed to know what they were doing. . . They showed me that we often do intervene too early and do not give children enough time to work through a problem themselves.'

These aspects of pedagogy which were considered significant by the teachers in the demonstration lesson were also consistent with those identified in the main study, with one exception. The issue of adult intervention stands out. This was identified as a significant factor by the teachers observing the demonstration lessons. It was not raised by the teachers involved in the main research, even though researchers observing the lessons in the main study had noted the negative impact of adult intervention.

\section{CONCLUSIONS AND IMPLICATIONS}

The use of demonstration lessons allowed the observing teachers to take on the role of researchers and analyse the impact of the use of puppets. In many professional development sessions it is difficult to enable that level of analysis to take place. Although for the presenter it can be risky, working with an unknown group of children in an unfamiliar context, the gains in terms of teachers' knowledge and understanding appeared to be significant. Within a short period of time the teachers were able to identify the value of using the puppets and recognise a number of factors, especially those relating to the role of the puppet and the teacher, as being significant in maximising the puppet's impact. The data also suggest that demonstration lessons might also help teachers to 
identify aspects of pedagogy that may go unrecognised in more typical circumstances, such as the impact of adult intervention.

Whilst the teachers observing the demonstration lesson did not identify any new issues relating to the use of puppets, the data from the case study confirmed the positive impact of using puppets in science lessons, even in the rather unusual circumstances of children being observed by a large group of teachers. There were strong parallels between the main study and case study teachers' views of the value of the puppets and the reasons why the puppets had positively influenced teaching and the children's engagement.

Both groups identified the need for the puppet to take on a low status rather than an expert role, and to be unsure about what to do. This allowed the children to empathise with the puppet and created an obvious purpose for their scientific activities. Children themselves recognised the significance of this factor. As one 11-year old child described, 'The teacher already knows the answer anyway. So she's really just testing you. The puppet doesn't know the answer so we have to explain it in a way he will understand.'

Teachers in both studies noted that puppets create the opportunity to present authentic problems rooted in children's everyday experience, enabling them to readily identify with the problem and with the puppet character. They described the teacher's role as needing to be non-judgemental, so the main responsibility for solving the problem was the children's.

During the main study, as the teachers used their puppets they began to recognise that it was important to provide time and space for discussion if they were to promote learning conversations amongst children. Consequently discussion time increased in their lessons. One teacher described how he normally took on a didactic role in teaching science, but when using puppets he thought more about getting the children to talk with each other rather than just to him. Another teacher said she had planned more talking tasks with the puppets, and that previously 'I didn't give them opportunities to talk even if they would. I didn't know whether they would (talk) because I didn't give them many opportunities to talk, so that's definitely increased the amount of time for talking.' After observing only one demonstration lesson the case study teachers were also able to identify the importance of this issue.

It was notable that there was one issue where the case study teachers identified an aspect of pedagogy not raised by any of the main study teachers. In the main study the researchers had noted the negative impact of many adult interventions. Children who were deep in discussion, or working out in their own way how to address the puppet's problem, either ceased their conversations or changed the nature of what they were discussing. It seemed as though they stopped their discussions in order to allow the adult to take charge. This issue has not been easy to convey through more traditional professional development sessions within the PUPPETS project. However, in the demonstration lessons this issue was identified as important by the teachers, without any prompting. Some of the teachers noted that they experienced significant tension and discomfort because they were asked not to intervene. However, they were able to reflect on this response, recognise that the children were able to progress very effectively with minimal teacher intervention, and identify for themselves that adult intervention may not have the positive impact that they expected.

The idea of using demonstration lessons as a means of professional development was viewed positively by the observing teachers. The expert teacher leading the demonstration does need a high level of expertise and confidence to work in front of a large audience of teachers, especially in circumstances where there is no prior relationship with the class of children involved in the lesson. However in many respects this arrangement closely models an authentic classroom experience, with the observing teachers able to select which children to observe and target their attention on 
specific aspects of the lesson. This puts teachers in the role of researcher, enabling them to identify what was significant about the professional practice they observed (Feger, Woleck \& Hickman, 2004). The risky, real-time nature of the lesson, coupled with the outcomes not being known in advance, gives the demonstration lesson a sense of reality which video evidence rarely achieves. Teachers are provided with a common experience for discussion and reflection, and this provides a good basis for grounding issues about professional practice in a real context (Loucks-Horsley et al, 2003). The interactions amongst the group of teachers bring a variety of perspectives to the discussion, leading to greater understanding of the professional issues raised and an increased willingness to reflect on their own professional practice (Loucks-Horsley et al, 2003).

Proper debriefing after a demonstration lesson is viewed as an essential element of professional development (Adey, Hewitt, Hewitt \& Landau, 2004; Feger et al, 2004). In this case study the discussion at the end of the demonstration lesson was essential in providing an opportunity for identifying the pedagogic principles that underpinned the lesson. These principles emerged naturally through the discussion, as part of the explanation generated for how and why the lesson took the course that it did. They were not put forward as a direct challenge to the teachers' values, beliefs or professional practice, but identified as what appeared to work well in a lesson that they had all observed together. The evidence of the effectiveness of the lesson was impossible to dismiss, especially in the challenging circumstances in which the expert teacher was required to work. As Feger et al (2004) put it, 'for some teachers, seeing is believing'. The question of whether the teachers should implement these pedagogic principles in their own teaching was left implicit, but was clearly a question that they were expected to confront. If any of the teachers went on to change their professional practice as a result of the demonstration lesson, then this change would be due to the teacher's inherent self-motivation, not because of any external requirement. These changes would be more likely to be long lasting.

The structure of the demonstration lesson used in this study represents a very different type of pedagogy from some science lessons, in which a problem is posed by the teacher, the method of solving the problem is directed by the teacher, the teacher determines the significance of any data collected, and the teacher guides the class towards a conclusion. It therefore presents a significant professional challenge for some primary teachers, since they may well find that their usual expectations and beliefs about how a good science lesson is structured are called into question by the demonstration lesson.

The literature on teacher change suggests that change in teacher practice can be difficult to achieve in a short period of time (e.g. Adey et al, 2004; Fullan, 2001). However, we know from our earlier research (Naylor, Keogh, Downing, Maloney \& Simon, 2007), and evaluation of the PUPPETS Project professional development programme, that short professional development sessions on using puppets have had a surprisingly large impact on teacher professional practice. Demonstration lessons appear to have had a similar impact over a short period of time ( 2 hours), by providing direct experience and evidence for teachers, enabling them to envisage the means and consequences of changing aspects of their professional practice.

The demonstration lessons do appear to provide some additional benefits for teacher development. It is evident that some aspects of pedagogy can be difficult to communicate, or may go unrecognised by teachers. Observing a demonstration lesson takes away the emotions that would be associated with teachers making critical judgements about their own professional practice, and provides a degree of objectivity that is difficult to obtain otherwise. The impact of teacher intervention in particular is very difficult for teachers to analyse in their own classrooms, since it is not easy to obtain data on how children interact without being there to observe them. This issue formed a natural part of the teachers' reflections and created obvious cognitive conflict for some of them. 
The use of demonstration lessons does appear to be a viable model for teacher professional development within the PUPPETS Project, providing one possible mechanism by which the positive results of the main study might be used to influence professional practice. The local authority adviser and expert teacher believe that the professional gains made by the teachers outweigh the demands of organising the lessons. Although it is not possible to be confident about the transferability of this model to other professional development programmes, this case study suggests that it is an option worth considering.

There is already some anecdotal evidence about changes in the teachers' professional practice as a result of the experience. Further feedback will be obtained about whether the positive comments made at the time are translated into professional action in the classroom.

\section{REFERENCES}

Adey, P., Hewitt, G., Hewitt, J. and Landau, N. (2004). The professional development of teachers: practice and theory. Dordrecht: Kluwer Academic.

Alexander, R. (2006). Towards dialogic teaching. York: Dialogos.

Feger, S., Woleck, K. and Hickman, P. (2004). How to develop a coaching eye. JSD, 25(2).

Fullan, M. (2001). The new meaning of educational change ( $3^{\text {rd }}$ edition). London: RoutledgeFalmer.

Keogh, B. and Naylor, S. (2007). Spellbound Science 1. Sandbach: Millgate House Publishers.

Kuhn, D., Shaw, V. and Felton, M. (1997). Effects of dyadic interaction on argumentative reasoning. Cognition and Instruction, 15(3), 287-315.

Low, J. and Matthew, K. (2000). Puppets and prose. Science and Children, 37(8), 41-45.

Loucks-Horsley, S., Love, N., Stiles, K., Mundry S. and Hewson, P. (2003). Designing professional development for teachers of science and mathematics. Thousand Oaks: Corwin Press.

Mercer, N., Wegerif, R. and Dawes, L. (1999). Children's talk and the development of reasoning in the classroom. British Educational Research Journal, 25(1), 95-111.

Naylor S., Keogh B., Downing, B., Maloney, J. and Simon, S. (2005). The PUPPETS Project: using puppets to promote engagement and talk in science. Paper presented at the European Science Education Research Association Conference, Barcelona, Spain.

Naylor S., Keogh B., Downing, B., Maloney, J. and Simon, S. (2007). The PUPPETS Project: puppets and change in teacher practice. Paper presented at the European Science Education Research Association Conference, Malmo, Sweden.

Newton, P., Driver, R. and Osborne, J. (1999). The place of argumentation in the pedagogy of school science. International Journal of Science Education, 21(5), 553-576.

Osborne, J. and Simon. S. (1996). Primary Science: Past and Future Directions. Studies in Science Education, 27, 99-147.

Shakespeare, D. (2008). PUPPETS - talking science, engaging science: an evaluation of the project. London: Nuffield Foundation.

Simon, S., Naylor, S., Keogh, B., Maloney, J. and Downing, B. (2008). Puppets promoting engagement and talk in science. International Journal of Science Education, 30(9), 1229-1248.

Solomon, J. (1998). About argument and discussion. School Science Review, 80(291), 57-62.

Strauss, A. and Corbin, J. (1998). Basics of Qualitative Research. London: Sage Publications.

Thorp, G. (2005). The power of puppets. Trowbridge: Positive Press.

Venville, G. (2002). Enhancing the quality of thinking in Year 1 classes. In M. Shayer \& P. Adey (Eds.) Learning Intelligence. Buckingham: Open University Press.

Vygotsky, L. S. (1978). Mind in society: the development of higher psychological processes. Cambridge, MA: Harvard University Press. 